\title{
Politeness Strategies Employed towards Linguistic Taboos in Tlemcen Society
}

\author{
Nadia Ghounane*, Ilhem Serir-Mortad, Hanane Rabahi \\ Tlemcen University, Tlemcen, Algeria \\ Email: *nadoushben@ymail.com
}

How to cite this paper: Ghounane, N., Serir-Mortad, I., \& Rabahi, H. (2017). Politeness Strategies Employed towards Linguistic Taboos in Tlemcen Society. Open Journal of Modern Linguistics, 7, 217-228. https://doi.org/10.4236/ojml.2017.75016

Received: August 11, 2017

Accepted: September 16, 2017

Published: September 19, 2017

Copyright @ 2017 by authors and Scientific Research Publishing Inc. This work is licensed under the Creative Commons Attribution International License (CC BY 4.0).

http://creativecommons.org/licenses/by/4.0/

\section{(c) (i) Open Access}

\begin{abstract}
The current research paper tends to shed light on the use of politeness strategies to avoid the harmonious power of some taboo topics and expressions. In this sense, the present research work provides an in-depth look on the position of these strategies in Tlemcen culture and language use. To this vein, the focal point of this paper revolves around the polite forms that Tlemcen speakers resort to use them in order to express their respect and request for something or to avoid face threatening act when discussing certain taboo themes. To this end, an investigation of politeness strategies in Tlemcen society was made through the help of a questionnaire and a focus group interview. Thus, the outcomes of this study showed that politeness constitutes an indelible part in Tlemcen culture. Tlemcen speakers employed politeness strategies in both family and society to show respect and protect their faces. The results also revealed that they had recourse to polite forms to euphemise sexual matters that are considered to be the most tabooed subject in Tlemcen culture.
\end{abstract}

\section{Keywords}

Politeness Strategies, Linguistic Taboos, Brown and Levinson's Model, Tlemcen Society

\section{Introduction}

The use of politeness in daily speech interaction has attracted researchers from sociolinguistics and pragmatics or socio-pragmatics which take into consideration the relation between speakers in relation to their gender, age and socio-cultural background. Consequently, this leads to the emergence of many studies like Goffman (1967), Brown and Levinson (1987) that focus on exploring how people build their linguistic forms in their daily interaction and protect their faces during communication. Besides, individuals are always looking after 
their speech fearing that it may lead to loosing face; hence Brown and Levinson (1987) postulated politeness framework that explores the use of politeness strategies $^{1}$ to strengthen social relations.

To this end, the choice embarking upon this research paper sprang from the fact that Algerian varieties in general and Tlemcen dialect in particular are rich in polite forms that need to be explored from a sociolinguistic point of view. Thereby, this research work aims at investigating the different politeness strategies employed by Tlemcen speakers. Herewith, this research work attempts to explore how Tlemcen speakers protect their faces when they are discussing taboo topics. From the foregoing discussion, our research enquiries fall on the ensuing research questions which are presented as follows:

1) Do Tlemcen speakers resort to politeness strategies in their social interaction? In other terms, do they use polite forms to save their face during their daily interaction?

2) What are the reasons that drive them to employ polite forms? Stated differently, what are the social motives that push Tlemcen speakers to resort to polite expressions?

3) What are the most tabooed topics that need the use of politeness strategies? Are sexual matters the most tabooed topic that needs polite forms?

Taking into consideration the above questions, the following hypotheses can be put forward:

1) Polite forms constitute a paramount place in Tlemcen society's social norms and traditions. Henceforth, speakers resort to use them either for requests or to protect their faces.

2) Respect is the first reason that drives all people to employ polite forms in their communication. Tlemcen speakers are always looking after protecting their faces and strengthen their social relations.

3) Sexual matters are regarded as the first tabooed subject that needs to be euphemised through the use of polite forms. Death and age are other topics that have taken a special place in Tlemcen culture; consequently, speakers construct a rich lexis to utilise as a part of politeness strategies.

\section{The Face-Saving View: Brown and Levinson's Model of Politeness}

Probably the most widely used model to politeness is that of Brown, and Levinson, who have derived their theory from Grice's Cooperative Principle. They argue that speakers in all languages need face saving as an important part of human interaction. They, further, state that most of people resort to polite strategies that express solidarity, respect, and protect both the speaker' and the hear-

${ }^{1}$ Politeness strategies: are words and expression that Algerian society and Tlemcen speakers employ in their daily interaction in order not to loose their face in their social interaction. These strategies are taken from Islamic teachings since it is an Islamic society. The concept of politeness in Arab societies differs from that of Western societies. It is related to dignity and the concept of shame

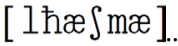


er's faces. Coming to these strategies can minimise threat during the core of daily conversation, Brown and Levinson propose "a Model Person" endowed with rationality and face. They also introduce the concept face which is "the public self-image that every member wants to claim for himself” (Brown and Levinson, 1987: p. 66). In this context, face may be defined as the social value that an individual has taken to strengthen social ties with other members of his society. From his perspective, Goffman (1967: p. 5) suggests that it is a rule for speakers to respect the lines of communication to maintain their faces. This statement is better explained through his words as follows:

The combined effect of the rule of self-respect and the rule of the considerateness is that the person tends to conduct himself during an encounter so as to maintain both his own face and the face of other participants.

Additionally, face can be divided into negative and positive. According to Brown and Levinson (1987), positive face is "the positive consistent self-image or "personality" (crucially including the desire that this self-image be appreciated and approved of) claimed by interactants", whereas negative face is "the basic claim to territories, personal preserve, rights to non-distraction-i.e. to freedom of action and freedom from imposition" (p. 66).

Interestingly enough, Brown and Levinson assert that the notion "face" is associated with what is called "face wants". Positive and negative are not associated with good or bad. In his part, Arendholz (2013) argues that the first is linked to the need to be accepted, whereas the second focuses on the person's freedom "of action, and not to be imposed on by others" (p. 60).This means that positive face is essential in developing social ties. In this vein, Tannen (1992, p. 15) illustrates this view as follows:

We need to get close to each other, to have a sense of community, to feel we're not alone in the world. But we need to keep our distance from each other to preserve our independence, so others don't impose on or engulf us. This duality reflects the human condition. We are individual and social creatures. We need other people to survive, but we want to survive as individuals.

As quoted in Arendholz (2013: p. 60).

As suggested in the above statement, Brown and Levinson's central aim is to maintain each other face against any threat, and to mitigate it in order to prevent face damage. Moreover, they (1987) state that people tend to maintain their faces either in written or spoken communication. In the other word, they try to avoid making each other embarrassed. For this reason, they introduce the concept of Face Threatening Act (FTA). At this point, Brown and Levinson distinguish between two types of FTA. The first one addresses the hearer or speaker, and the second focuses on positive and negative face. In this account, politeness as a theory is developed for the purpose of dealing with FTA. Although it suffers from many drawbacks, it has gained the interest of some stylists in analysing li- 
terary discourse.

Interestingly enough, Brown and Levinson argue that certain acts can bring the risk of damaging the speaker's face, thus threatening the public self-image. In his part, Bouchara (2009) elucidates the view claiming that expressions of insults, and terms of abuse threaten the speaker's negative face, hence his public self-image. He adds that FTA is linked to some parameters including the context of interaction, the social relationship of the speaker, and the amount of imposition that an act contains. He, further, states that to carry out an FTA, a speaker may select one of the four strategies, especially Bald on-record, Off-record.

Focusing on the concept of face, Brown and Levinson introduce positive and negative politeness. The former is used to establish a feeling of solidarity between the speaker and the hearer, whereas the latter is intended by the speaker to maintain the hearer's negative face desires.

\section{Algerian Politeness Strategies}

The concept of politeness is linked to honour and the image of others in most Muslims societies. Indeed, politeness in Muslim culture in general and Algerian traditions in particular takes the face not only of the individual but also of all people in their society. In this regard, it is different from Western concept since it is also related firstly to the personal image, respect of the other, honour of the family and dignity. According to Edwards and Guth (2010), "Honour, dignity and self-respect are "sacred" concepts among Arabs since pre-Islamic times, and are considered taboos, which should not be abused by anybody" (p. 33).

Interestingly enough, one can infer the fact that Muslim culture has regarded politeness as an essential component in the individual's daily speech and behaviour. As a matter of fact, politeness has been seen as an essential medium that preserves the individual's honour and shame. In fact, these two concepts are the most important ingredients that direct politeness in the individual's daily interaction. They are considered as a part of social etiquette that determines the social relations between individuals and families. Besides, these social etiquettes do not only determine social relations but direct also the selection of politeness strategies and word choice.

Additionally, it is important to state that honour, as a part of politeness framework in Muslim societies, has always been linked to female sexuality. In other terms, the honour of females represents the honour of the family and any violation of the concept [el $\mathrm{i}$ ird] "honour", means violating the social norms of the whole society not only the family. Many scholars relate Arabic politeness to the terms [el iæðeb].

Arguably, politeness has always been accompanied by euphemistic strategies because Muslims are looking for substitutions to preserve their honour and dignity. In this vein, Alli (2011) highlights that Arab speakers employ euphemisms ${ }^{2}$

${ }^{2}$ Euphemisms: are used to discuss taboos indirectly. They are culture-specific since they differ from one culture to another. In Arabic culture, they are related to kindness [elotf] or [etæla:tof]. 
"to make remarks less direct, less blunt or harsh, and to add a touch of politeness to certain expressions which otherwise seem unpalatable and hard to digest" (p. 25-26).

Additionally, Algerian people take their polite forms from religious traditions. These terms are employed as polite forms such as [llah jarda Sliik]: "may God be pleased with you” or [llah jhћafdak]: "may God preserve you” or [llah jxali:k]: "may God live you”.

\section{Methodology}

The study under scrutiny is an exploration which relies on a blend of quantitative and qualitative research instruments mainly a questionnaire and a focus group interview.

- Quantitative: a semi-structured questionnaire was distributed to 200 participants from Tlemcen speech community. The rational behind the use of a questionnaire is to test their attitudes towards the different polite forms used by Tlemcen individuals in their daily speech.

- Qualitative: a focus group interview was conducted with 10 individuals from different genders, educational background and ages.

\subsection{Research Sample}

As it has already been mentioned before, the sample for this research work consists of 200 informants. The sample was selected randomly focusing on distinct linguistic variables mainly age and gender. The educational background of the informants is very important for collecting data. However, only 120 of the informants answered the questions of the questionnaire. Henceforth, they were classified into four categories depending on their age since there is a huge difference between young and old people in employing polite forms. The following table provides an in-depth look about the questionnaire and its participants:

As Table 1 demonstrates, the participants were selected depending on a simple random sample taking into account the two linguistic variables mainly age which is of eminent importance in collecting data in a simple random sample. Secondly, selecting the informant focuses also on gender because the terms used by individuals; for instance, to talk about death differ between males and females. Another important point is that gender and age are important variables

Table 1. Categories of Participants.

\begin{tabular}{cccc}
\hline Age & Females & Males & Total \\
\hline $18-25$ & 35 & 20 & 55 \\
$26-35$ & 05 & 15 & 20 \\
$36-45$ & 10 & 19 & 29 \\
Above 46 & 10 & 07 & 17 \\
Total & 60 & 60 & 120 \\
\hline
\end{tabular}


that cannot be separated in exploring language use in a given speech community.

\subsection{Data Analysis and Results Discussion}

Throughout the following analysis of both the questionnaire and the interview, we are going to explore the different polite forms and the attitudes of Tlemcen speakers towards these expressions.

\subsubsection{Questionnaire}

After the collection of the questionnaire, all the informants gave back their answers and supplied us with a rich lexis. Hence, the questionnaire was answered anonymously; however, the researcher is going to take four paramount questions for analysis in relation to the research questions stated above.

First Question: Do you employ polite forms in your daily interaction?

1) Yes

2) No

As it is demonstrated in Table 2 and Figure 1, most of the informants declared that they employ polite forms and strategies in their conversations, although both males and females differ largely in their attitudes towards the different politeness strategies. They also confirmed that the use of polite expressions differ even between the same sex depending on their age and educational background. Therefore, about $63.33 \%$ of the participants claimed that they em-

Table 2. Participants' use of polite forms.

\begin{tabular}{ccccc}
\hline Suggestions & Females & Males & Total & Expressed in \% \\
\hline A & 45 & 31 & 76 & $63.33 \%$ \\
B & 15 & 29 & 44 & $36.66 \%$ \\
Total & 60 & 60 & 120 & \\
\hline
\end{tabular}

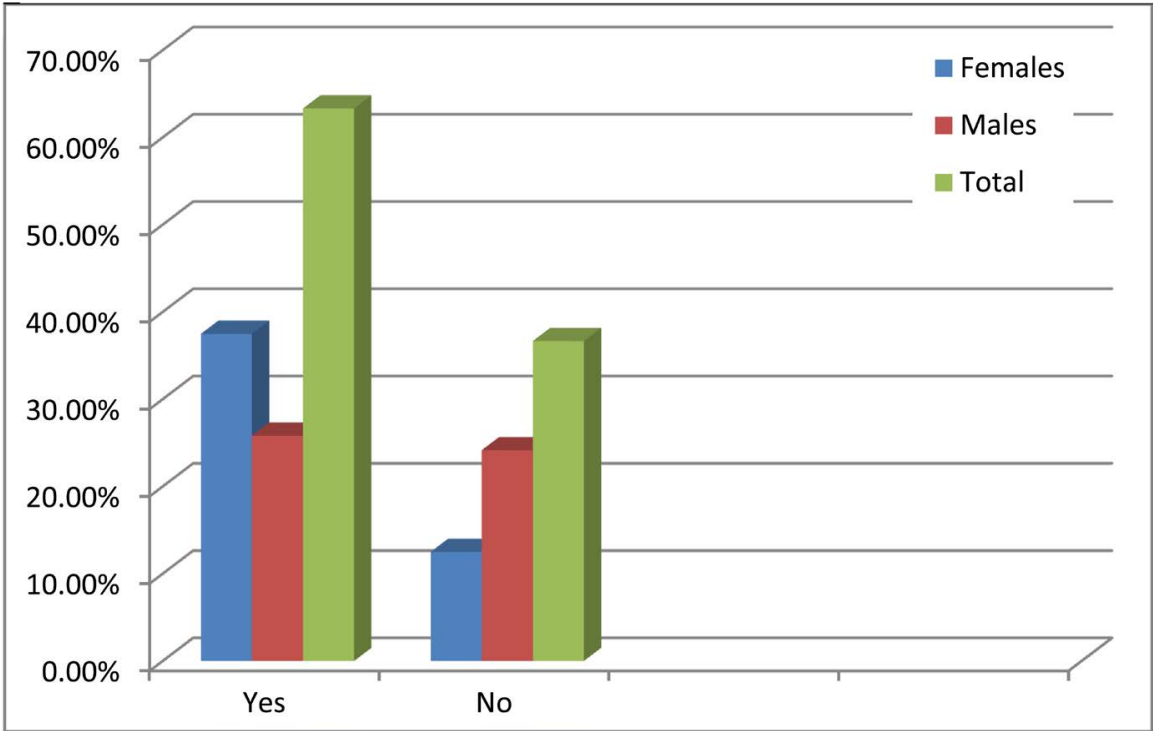

Figure 1. Participants use of polite forms. 
ploy polite forms and terms of address in their daily interaction depending on the subject being discussed, whereas about $36.66 \%$ of them argued that they do not use these expressions in their daily speech.

Question two: How often do you use politeness strategies?
1) Many times a day.
2) Every day.
3) Sometimes.
4) Rarely.

As Table 3 and Figure 2 have already explained, about $35.83 \%$ of the participants maintained that they employ politeness strategies many times a day, while $20 \%$ of them confirmed that they resort towards using polite forms every day. In fact males and females differ in using politeness since women have always to look after their language due to the conservative nature of the society that imposes on them to select the appropriate forms for their conversation.

Question Three: What are the reasons behind the use of polite forms in daily interaction?

1) To protect their faces.

2) To show respect

As Table 4 and Figure 3 show, most of the informants (71.66\%) shared the view that polite forms are employed to protect their faces. They declared that

Table 3. Frequency of using polite forms.

\begin{tabular}{ccccc}
\hline Suggestions & Females & Males & Total & Expressed in \% \\
\hline 1 & 28 & 15 & 43 & $35.83 \%$ \\
2 & 23 & 13 & 36 & $30 \%$ \\
3 & 05 & 12 & 17 & $14.16 \%$ \\
4 & 04 & 20 & 24 & $20 \%$ \\
Total & 60 & 60 & 120 & \\
\hline
\end{tabular}

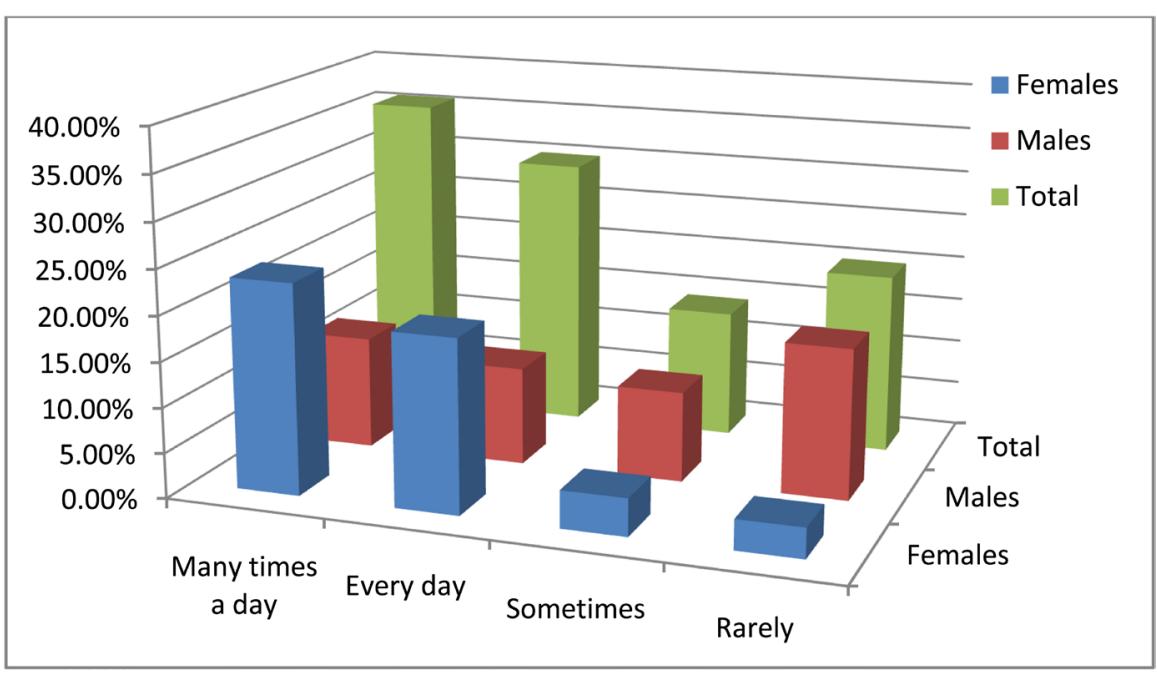

Figure 2. Frequency of using polite forms. 
Table 4. Reasons behind the use of polite forms in daily speech.

\begin{tabular}{|ccccc}
\hline Suggestions & Females & Males & Total & Expressed in \% \\
\hline 1 & 55 & 31 & 86 & $71.66 \%$ \\
\hline 2 & 05 & 29 & 34 & $28.33 \%$ \\
\hline \\
\hline
\end{tabular}

Figure 3. Reasons behind using polite forms in daily speech.

politeness strategies are used to lessen the use of taboos or in discussing some tabooed subjects such as sexual matters, while about $28.33 \%$ of both female and male participants agreed that politeness strategies are useful to reveal respect because they are parts of the religious standards and social norms of the society.

Question Four: What are the most sensitive topics that drive you to employ politeness strategies?

1) Sexual matters.

2) Death.

3) Age.

As it is revealed through Table 5 and Figure 4, the majority of participants under investigation shared positive attitudes towards the most tabooed topic that needs polite forms. They informed that sexual matters are regarded as the most tabooed subject in their society; for this reason it is euphemised and people tend to employ politeness strategies to avoid Face Threatening Acts and decrease the use of taboos. In contrast, about $20.83 \%$ of the informants maintained that death is not a taboo topic in Islam or Tlemcen speech community, but they tend to use polite forms for many reasons such as to show their sympathy with the family of the deceased or to reveal their grief for loosing a beloved person.

\subsubsection{Interview}

As it has already been stated, the interview was held with 10 participants from different ages, genders, educational backgrounds and occupations. The researcher 
Table 5. Participants' attitudes towards the most tabooed topics that need politeness strategies.

\begin{tabular}{ccccc}
\hline Suggestions & Females & Males & Total & Expressed in \% \\
\hline 1 & 43 & 50 & 90 & $75 \%$ \\
2 & 15 & 10 & 25 & $20.83 \%$ \\
3 & 02 & $/$ & 02 & $1.66 \%$ \\
Total & 60 & 60 & 120 & \\
\hline
\end{tabular}

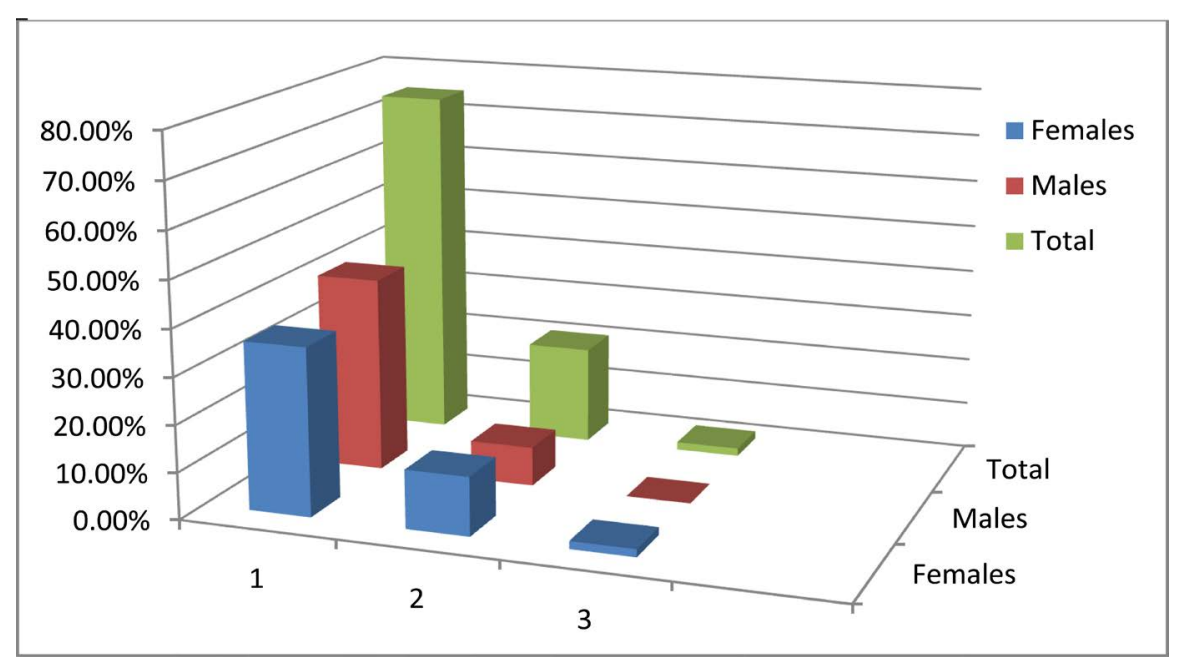

Figure 4. Participants' attitudes towards the most tabooed topics that need politeness strategies.

has taken the most important questions being asked during the interview depending on the research questions stated above. In fact, collecting data through the interview was quite hard due to the sensitivity of some questions. Hence, only 10 informants agreed to answer the questions. Their ages are between 25 and 60 years old.

Another important pointed that should be added is that the researcher focused on a focus group interview. Hence, he selected two groups of equal number from both sexes (five males and five females) in addition to differences in age and educational background, hoping that this may be helpful in collecting data

Additionally, one should state that the attitudes of speakers differ largely depending on certain sociolinguistic parameters mainly gender and age. Besides, one should also confirm that the use of polite forms is seen as an important part of Tlemcen speakers' daily interaction and social traditions. In order to lessen the harmonious power of taboo expressions, people resort to the use of euphemisms as politeness strategies to protect their faces.

Sexual matters are the first subjects to be euphemised because they are regarded as the first taboo topic that violates religious and social norms. Moreover, death is another topic, which is euphemised, although it is not regarded as a taboo subject. Therefore, the interview tried to investigate the position of polite- 
ness strategies in Tlemcen culture and society. It attempted also to throw some light on the polite forms that Tlemcen speakers employ to talk about sexual matters, death and age.

The researcher has taken the most important questions from the interview for the analysis throughout the current research paper:

First Question: Do Tlemcen speakers use polite forms to talk about death?

The finding of this question revealed that death is not a taboo topic, but it is treated with more care due to its sensitive nature; consequently, it is euphemised and people tend to utilise polite expressions such as [elmærhu:m] or [elmætwæfæ] (the dead). They also employed expressions such as [aleh jbædel mћæbtu besbær] or [slæ:mæ fi ru:skum] in order to be with the family of the deceased. The informants had also mentioned that Temcen speakers have developed certain expressions to talk about sudden death such as [fla:n ta:ht wræqtu], [fla:n næxtæf] or [fla:nða: ]].

Some of the interviewees mentioned also the question of age when discussing the subjects which are taboo in Tlemcen society. They added that age has taken a special position in Islam. Unlike Western tradition where old people are useless for the society, in Muslim society's age means wisdom. As a matter of fact, they highlighted that people have developed certain polite forms to express their respect to the old such as [elha:3] or[Sibæni]. While the first is used by Tlemcen speakers in urban places, the last is found in the dialect of rural people.

Second Question: What is the most tabooed sexual topic that needs you to employ polite forms?

The results proved that the views of the interviewees vary between words related to body parts, sexual intercourse and female issues. Four informants declared that body parts are regarded as the most tabooed subject that should be euphemised through the use of certain polite forms especially to talk about female body parts. In their part, three female participants maintained that female issues are seen as the most sensitive subjects; therefore, women should employ euphemisms to hide their meaning including virginity, menstruation, pregnancy and menopause, whereas the remaining informants claimed that sexual intercourse with its related subjects should not be discussed in public, and hence the society imposes some restrictions on it and people tend to discuss these matters through the use of euphemisms as a part of politeness strategies.

Third Question: Do people differ in using politeness strategies?

In this context, most interviewees argued that old people differ largely in the lexis they prefer to use in comparison to the young. The results of the interview demonstrated that young speakers tend to employ indirectness and more requests due to their respect to the old. They, further, highlighted that age plays a paramount role in request choice and the use of indirectness in speech. Another point that the interviewees mentioned is that the context of use has an eminent place in directing the use of politeness strategies.

To wrap it up, one can state that Tlemcen speakers have developed certain po- 
lite forms taken from Algerian culture and Islamic teachings for their daily use since they are always looking after protecting their faces and of course politeness has a paramount place in what is called in Arabic culture [el?æðeb].

\subsection{Data Interpretation and Recommendation}

In the light of what has been discussed through this current research paper, one should inform that the results of the questionnaire and the interview seem to be of paramount importance since they may serve as guidelines to know more about the position of politeness strategies in Tlemcen culture and dialect and the reasons that drive them to employ these linguistic forms in their daily speech.

First and foremost, the findings proved that Tlemcen speakers regardless their age or gender employ polite forms as a part of politeness strategies in their daily interaction since these forms constitute an indelible part in their culture.

Interestingly enough, the analyses had shown that Algerian polite forms are directed by two parameters mainly religion and social conventions. The findings also demonstrated that these are the major reasons that control and push Tlemcen speakers to employ politeness in daily interaction. Respect and fear of loosing dignity or loss of face are also seen as important features that drive them to resort towards polite expressions which in turn enrich Algerian varieties in general and Tlemcen dialect in particular since they are taken from religious traditions.

More importantly, the results also revealed that Tlemcen speakers are careful in approaching certain taboo topics mainly sexual matters. Henceforth, they utilise polite forms to reduce the negative power of these topics and avoid face threatening or negative politeness. In fact, sex and sexual matters are considered as the first taboo topic in Arabic culture and, therefore speakers try to decrease the harmonious power of discussing the subject in family or society or in mixed sex groups. Indeed, they are forbidden to be discussed in public or family.

In the same context, the analyses showed that Tlemcen speakers shared the same views concerning death and age. The first is not seen as a taboo topic, but they have developed certain lexis to daily interaction, while age has been given a special position since it is linked to wisdom and respect, i.e., old people are regarded as a source of life experience and wisdom.

The findings also demonstrated that the use of polite forms is connected with certain sociolinguistic variables mainly gender and age in addition to the context of use or the situation of the conversation, i.e., Tlemcen people employ polite forms in mixed sex groups or family members when they are discussing some taboo issues, fearing that they forfeit face and result in a FTA.

The results had also shown that Tlemcen speakers have a tendency towards terms of address to show positive politeness especially in requests such as: [elæh jxæli:k], [elæh jærdæ sli:k], [elæh jæSti:k esæћ⿸] or [elæh jærdæælli:k]. 


\section{Conclusion}

It is of crucial importance to note that the findings of this research paper are just some recommendations and suggestions that may help in exploring politeness and linguistic taboos in relation to culture and language use. As a result, politeness strategies differ according to gender, age and the socio-cultural back ground of each society.

Interestingly enough, the current research papers provides us with an overview about the socio-cultural traditions of Algerian society in general and Tlemcen speech community in particular. In the light of this idea, one can confirm that politeness strategies are culture specific since taboo topics differ from another culture to another.

From the aforementioned discussions, one can state that speakers have different attitudes towards the use of politeness strategies. These attitudes are connected with the speakers' gender, age and their socio-cultural background. All in all, these results cannot be generalised but they can be taken as a point of departure for more scholarship since this field lacks studies in the Algerian context. Indeed, few researches were conducted in this area of research.

\section{References}

Alli, H. (2011). Intimacy and the Sacred in Muslim Communities. USA: iUniverse, Inc.

Arendholz, J. (2013). (In)Appropriate Online Behavior: A Pragmatic Analysis of Message Board Relation. John Benjamins Publishing Company. https://doi.org/10.1075/pbns.229

Bouchara, A. (2009). Politeness in Shakespeare: Applying Brown and Levinson's Politeness Theory to Shakespeare's Comedies. Hamburg: Diplomica Verlag GmbH.

Brown, P., \& Levinson S. C. (1987). Politeness: Some Universals in Language Usage. Cambridge: Cambridge University Press.

Edwards, L., \& Guth, S. (2010). Verbal Festivity in Arabic and other Semitic Languages. Deutsche Morgenlandiche Gesellschaft Harrassowitz Verlag.

Goffman, E. (1967). Interaction Ritual: Essays on Face-to-Face Behaviour. Garden City, New York: Anchor. 